\title{
The impact a metaphor can have on one's followers
}

\section{Srishti Jain}

MBA Marketing and sales, Amity Business School, Amity University, Noida, India

\begin{abstract}
Within an author's tools and techniques; metaphor is indeed an important weapon. Using metaphors very well but the followers may adapt to your literature or creative writing over a reflexive and larger level. A literary term in which anything is related or otherwise matched to whatever it captures creates a confidential, hidden connection from a metaphor. Adopting idiomatic phrases provides everyone a wonderfully realistic description of something like a better to focus of vibrant, shiny concepts which do not co - exist through patterns. This research focused upon or explains turn of phrase as both a relational and a textual methodology which helps to build interpretation. For something like a creator, it's just a way to influence speech in how audience contributes. Phrase helps a creator to regulate how viewers interpret what is being released. Any metaphor will have the function of expressing something in a form which brings strength and toughness on everything so it can be used by a successful writer to demonstrate the perspective of a story and also some highlight the standpoint of every protagonist. Metaphorical terminology stimulates creativity, as well as the speaker will become more capable of conveying feelings and thoughts by metaphor. Metaphor communicates concepts even though there is no common vocabulary, as well as encourages learners to question descriptively.
\end{abstract}

Keywords-Metaphor, Creator, Audience, creativity, interpretation.

\section{INTRODUCTION}

Metaphor is a concisely or ideologically creative need for statements, which again is conceptual rather than philosophical. These have fascinated extra conceptual desire to participate and impacted more literary debates than some of the other generally addressed speaker recognition symbols. Because we use metaphor, we attempt to communicate regarding two aspects instantly; two separate and distinct subjects are combined with a vibrant and uncertain impact. Some of these subjects would either be undergoing negotiation or at minimum being already regarded whenever a participant suddenly converts towards metaphor. Whether we discuss how and when to connect main and secondary issues through being spoken about together in such a metaphor, it seems reasonable to suggest that metaphor is a means of interpretation and reference. Almost all of the influence and relevance of many a perfect symbol reflects the fact that perhaps the two groups are dramatically and prominently opposite, to both the reason whereby metaphor is most often identified by anyone with minimal aspirations to individuality as "a description of two separate subjects." The understanding of a metaphor does not always transform to characteristics that the opposing subject actually has and even to anything that it is presumed to have.

\section{METHODOLOGY AND RESULT}

It has been proved since reviewing a bunch of documents that Even a paragraph description usually likes certain aspects or qualities at a separate conceptual gesture to plenty of other aspects or sorts. Only within context of a provided turn of phrase, we fairly quickly clearly differentiate among both words and expressions to really be taken symbolically then to be interpreted correctly only. A lot of people claim To consider taking interpretation metaphorically becomes the place to turn it literately, as well as to take an expression literately is to contextualize it, to characterize everything in a way that moves away but continues to remain made aware by another contextual information metaphorical construct of it. Regular intervals, scholarly theorists question the role of extended metaphors, unified symbolic similarities spreading across various thinking. Metaphors which really served their 
purpose and within restricted scope of a single sentence or expression or part of speech are often contractual. They mostly genuinely express her once differentiated metaphors become mixed into strong, managed, anything else but delightful potential impact not all statement symbols in either way assume the shape of complete statements: metaphorical suggestions, literal directions, metaphorical operatives, etc. This creation is very new. Philosopher and rhetoricians interpreted metaphors as an immediate self-explanatory improvement in the utilization of something like a particular or single word, usually an expression with a noun or synonym. If we use metaphor, a word that passes commonly for one element with another is now expected to stand for the next, sufficiently similar or equivalent, and even this shift in whatever the word represents. Often we turn to metaphor although this issue we would like communicate with has almost no existing definition without need to build a new word that can apply to it here and now. So well and so curiously, we respond to symbols both for the comfort everyone's listener will start taking in troubling everything out, the character it requires us to follow in recognizing our listener, and the based on crispness it needs to bring with some of its additional assistance to either the public's concern with whatever designers assume. The hard work to reclaim a basic special meaning speaks for such a valuable, enjoyable, sophisticated effort and dedication from others. The term we seek to recognize should represent everything plain and uninspired that can be expressed effectively through putting an end to metaphor, but the attempt to reclaim this definition has a good reward that overcomes the sense.

\section{CONCLUSION}

One phrase consequence is to create learning enjoyable. Helping to make vocabulary more colorful and fascinating, it will have the result of causing the audience delightful or enjoyable, or enjoyable to watch, helping make everyone to see everything in a pretty much the entire new perspective. Through means of metaphor, a writer can build specific meanings and require changes and significance to the way these things have been seen to work far better than accurate explanations. Adding metaphor allows the presenter to start creating thinking-related images, and use phrase to stunning real impact. One influence of the metaphor on either the audience is whether it promotes communication and understanding - since metaphor provides much more traditional meaning, it can give a reader a broader understanding of these than any practical interpretation.

\section{REFERENCES}

[1] Dorst, A. G. (2011). Metaphor in Fiction. 395.

[2] English writing techniques. (n.d.). Retrieved from wordy: https://www.wordy.com/writers-workshop/english-writingtechniques/

[3] Examples of Similes. (n.d.). Retrieved from your Dictonary: https://examples.yourdictionary.com/examples-of-similes.html

[4] Jensen, D. F. (2006). Metaphors as a Bridge to Understanding Educational and Social Contexts. International Journal of Qualitative Methods , 14-17.

[5] WEARING, R. C. (2014). Metaphor, hyperbole and simile. 31.

[6] Why Do Authors Use Metaphors? How Metaphors Ignite Imagination. (n.d.). Retrieved from https://austinhackney.co.uk/: https://austinhackney.co.uk/2016/10/18/why-do-authors-usemetaphors-how-metaphors-ignite-imagination/ 